\title{
Research on the Final Evaluation Model of the Teaching Effect of English Education Teachers in Huhhot Vocational College
}

\author{
Chao Zhao \\ Hohhot Vocational College, Inner Mongolia, 010000, China
}

\begin{abstract}
Teaching evaluation is an important link in teaching. Objective and scientific teaching evaluation can effectively help teachers understand the advantages and disadvantages in teaching, which is conducive to the development of effective teaching, and it has a positive impact on the teaching of English education teachers. In this paper, through the relevant model of teaching effectiveness of teachers, to identify the important factors impacting teaching evaluation in order to achieve the objective evaluation on the teaching of English education teachers in Huhhot Vocational College.

Keywords: English education; professional teachers; teaching effectiveness; summative evaluation; empirical study
\end{abstract}

\section{Introduction}

China's current teaching effectiveness evaluation method is relatively single, the evaluation system is imperfect, seriously affecting the evaluation of teaching objectivity and impartiality, the teachers did not play the incentive effect, is not conducive to improving the quality of English teaching and education objectives. In recent years, China's experience of foreign advanced teaching evaluation, the implementation of formative evaluation program, the teachers have an incentive effect, however, the concept of traditional Chinese examination-oriented education deep-rooted, the teacher's final evaluation is still based on student learning achievement evaluation of teaching effectiveness The students' performance has become an important factor in restricting the evaluation of 
teaching effectiveness, which is not conducive to providing effective teaching information to students. Students' feedback on teaching effect is not always positive and objective, and is not conducive to improving teaching quality and students' learning efficiency. In this paper, the significance of the final evaluation of English teachers 'teaching effectiveness is expounded, and an effective final evaluation data model is established to evaluate the English teachers' teaching effectiveness.

\section{The connotation and significance of the final evaluation of English education teachers' teaching effect}

\subsection{The connotation of the final evaluation of the teaching effect of the English education teachers}

The summative evaluation in teaching is usually focused on the end of the semester. The teaching effect is evaluated by the form of numbers, such as scores and grading. The emphasis is on the students' understanding of teaching, and the results of the students are measured. Evaluation contains a lot of information, is an important part of education, with a real and significant features, but the end of the evaluation to a certain extent, the students cheating, plagiarism and other unethical behaviour to provide an opportunity to make adjustments in time. The final evaluation is mainly through the students 'classroom performance and evaluation of teaching methods and teachers' teaching style, reflecting the teaching objectives and teaching practicality, the formal evaluation of teaching effectiveness, with strict supervision and the formation of plans, generally in the academic departments and the relevant major departments to coordinate and cooperate, but the end of the evaluation system does not provide feedback and recommendations on teaching effectiveness.

\subsection{The significance of the final evaluation of the teaching effectiveness of English education teachers}

Teaching evaluation is an important part of the teaching, objective and scientific evaluation of teaching is conducive to teachers to actively improve teaching measures, innovative teaching ideas, improve teaching methods to ensure the quality of teaching. The evaluation of teachers' teaching effectiveness is mainly from two aspects, including the evaluation of the teaching effect by the students and the evaluation of the teaching effect by the teachers of the school teaching and research group, including the formative evaluation and the final evaluation. Teaching evaluation is the feedback of teaching effect, which can reflect the shortcomings and advantages of teaching. And the lack of effectiveness of motivation, student achievement, including student learning and enthusiasm of the individual, but also the level of education of teachers, which is caused by two factors in common, so the end of evaluation is still not achieved good evaluation 
results, It is necessary to consider the influence of student factors on teachers' teaching effect, and to reflect the objectivity of teaching evaluation.

\section{The present situation and the solution to the final evaluation of the teaching effect of the English education teacher}

Due to the deep influence of the traditional exam-oriented education concept, the students, parents and teachers pay too much attention to the students 'academic achievement, which leads to the misjudgment of the scores. The students are faced with the pressure of examination, which seriously affects the students' daily life. The final evaluation of teaching effectiveness is an important part of teaching, for the self-development of students and teachers of teaching feedback. But the end of the current evaluation of the face of important difficulties needs to be resolved in order to truly improve the quality of teaching.

\subsection{The status quo of final evaluation of English education teachers' teaching effect}

The end of the evaluation of the effectiveness of English teachers teaching At present, the following two important questions: First, the excessive emphasis on the level of student achievement is the feedback of teaching. Students' test scores to a certain extent, can indeed reflect the quality of teaching and teaching effectiveness of students in the examination results include the hard work of teachers to pay, but also the results of individual efforts of students, but the onesided test scores as a teaching evaluation Is not a scientific evaluation of the concept and evaluation methods, a serious neglect of the teacher's teaching style and teaching attitude, as well as the student's learning function, and on the teacher's evaluation of teaching effectiveness is not the objectivity.

\subsection{The specific measures of final evaluation of English education teachers' teaching effect}

Teachers in the teaching of students play the guiding role in meeting the needs of students to play its learning function. Therefore, the administrative department of the school in the evaluation of the teaching effectiveness of teachers, the end of the evaluation system should be adjusted and improved to eliminate the objective factors of students, the relevant teaching staff should end the evaluation of the results of students focused study, the student expectations and Teaching staff expectations consistent, reflecting the teaching of teachers in teaching style and teaching attitude. And play different roles according to the different roles of teachers, when the teacher as a living assistant coach to help students learn to promote their learning progress; when the teacher as a juror or judge role, the performance of the students should inform the parents. The advantages of the two evaluation system will be integrated into the task of teaching them to achieve classroom goals, improve teaching quality and teaching level. 


\section{The data model for the final evaluation of the teaching effect of the English education teacher}

\subsection{The final evaluation of English teaching effect}

The evaluation of English teachers 'teaching effectiveness is based on the students' English learning achievement, which is usually concentrated in the end of the semester, and the CET test scores in the university. According to the syllabus, the students have accumulated knowledge structure and experience standardization. It is the feedback that the school administration department uses relevant means to the English teaching, and carries on the instruction to the English teaching, inspects, examines student's spoken English expression ability as well as reads and writes the ability. According to the results of the examination for the evaluation of teaching effectiveness to provide a large number of digital basis and the school or class in English to improve the actual learning situation, thereby enhancing students' language ability and oral expression.

\subsection{Establish the model based on the target pass rate of English teaching effect}

The key exams in English teaching are the college entrance examination and the CET4 and CET6 in the university. These test scores have become the important evaluation basis for the English education major. According to the digital model of the college entrance examination and university CET achievement goal passing rate, Response teachers' teaching effect, and make the final evaluation to teachers. In this paper, the college entrance examination in English and CET scores as a model of the sample, the survey found that students in the College Entrance Examination English score of 135 or more (out of 150 points) students in the university two years of English learning is easy to pass the CET level examination, And college entrance examination in English scores below 65 points is difficult to pass the University of CET grade examination, and thus get the argument, the University of English CET level and the level of college entrance examination achievement in English is closely related, it is not difficult to draw students CET The level of examination and the college entrance examination results in English is a positive correlation.

Remove the uncertainty of the outside world, the teaching effectiveness of the scientific, objective and reasonable evaluation. The teaching effect evaluation of teachers is divided into three grades: excellent, good and bad. The grading of grades is based on the ratio between actual passing rate and target passing rate. When the actual pass rate than the target pass rate in more than one percent, can effectively reflect the English teacher's teaching is better, can be rated as excellent teachers; when the actual pass rate than the target passing rate of $1 \%$ If the actual passing rate is less than one percent of the target rate, that is, the English teacher's teaching effect is poor, the grade of the teacher is rated as the grade of the teacher, and the grade of the teacher is rated as difference. 


\section{Conclusion}

This article through the final evaluation of English teaching professional teachers to establish the target pass rate data model, comparing the students' college entrance examination results in English and CET grading test results to make the English teacher's teaching objective, scientific evaluation, according to the different levels of school learning and knowledge of the specific structure of the data to be modified to reflect the school's English education professional teaching effectiveness, but also reflect the actual teaching level of the school. According to the shortcomings of the over-emphasis on the students' test scores, the application of data model can make up for their shortcomings, and also can reflect the teaching level and teaching effect of the teachers. Concerned about the student's academic performance not only reflects the progress of students, but also reflects the quality of teaching teachers, teachers have an incentive effect to meet the overall development needs of students, and fully tap the students internal potential and make a complete summary for the teaching task.

\section{References}

[1] Hu Jun. An Empirical Study of the Effectiveness of Vocational English Teaching from the Perspective of Textbook Evaluation, Vocational and technical education. 55(12), pp.68-70, 2011

[2] Wang Yong. Chinese and Foreign Teachers' Cooperative Teaching Research: A Review and Prospect (1992-2013) - A Study Based on CNKI. Chinese Foreign Language, 8 (5), pp.87- 91, 2013

[3] Xu Xiaofang. The Background Characteristics of Teachers and Evaluation of Teaching Effect in Colleges and Universities - An Empirical Study Based on Application-oriented Institutions of Higher Learning. Higher Education Research. 12(10), pp. 18- 20, 2012

[4]Liu Ping. Research on the Effectiveness of Network Self-regulated Learning in the Trinity Teaching Mode. Audio-Visual Education Research 9(6), pp.58-61, 2011

[5] Lu Wenyi. The Composing and Developing Trend of Hotspots in the Teaching of College English Reading Comprehension: Based on the Co-word Visualization Analysis of CNKI Academic Journals from 2001 to 2014, Foreign Language Teaching, 8(4), pp.85-87, 2014 